\title{
A tensão entre 0 cuidar e o violentar: vivência de filhos com pais velhos
}

\author{
Verônica Bohm, ${ }^{1}$ Sergio Antônio Carlos,${ }^{2}$ Johannes Doll ${ }^{3}$
}

\section{Resumo}

Cuidar de pessoas mais velhas tem sido uma realidade cada vez mais presente na sociedade atual diante do envelhecimento populacional. Muitas vezes, esse cuidado é feito por familiares, que assumiram tal tarefa sem um preparo para isso, o que pode ocasionar maior tensão na relação entre cuidador e cuidado. Ciente dessa situação, propõe-se neste artigo discutir um aspecto quase invisível e silenciado da violência, aquela violência que ocorre quando alguém está cuidando de/convivendo com um velho. Para tal, é feita uma articulação entre duas pesquisas, sendo uma sobre histórias de vida de cuidadoras de idosos e outra sobre a violência contra velhos na perspectiva de agressores. Os resultados apontam para a importância da construção de relações de qualidade entre os membros familiares, bem como para o diferente significado que uma ação violenta pode receber em decorrência da relação entre cuidador e cuidado.

Palavras-chave: Cuidador. Idosos. Violência.

\section{Tateando a violência contra velhos}

O tema da violência, devido à sua gravidade e à sua complexidade, tem sido pauta de diferentes discussões nos últimos anos, não apenas no Brasil, sendo abordado por meio de diferentes vieses. Violência no trânsito, violência contra mulheres, crianças, indígenas, velhos, homofobia, racismo, guerras religiosas, tráfico de drogas, alcoolismo, violência escolar, são muitas as pessoas que estão expostas e que sofrem violências diariamente, o que nos leva a afirmar que a sociedade atual está violenta, e há a necessidade de ser feito algo para reverter essa situação. Em nota técnica divulgada pelo Instituto de Pesquisa Econômica Aplicada (Ipea) (CERQUEIRA, et al., 2016), essa constatação ganha res-

1 Psicóloga. Mestre em Psicologia Social e Institucional, doutora em Educação (Ufrgs). Professora do Departamento de Psicologia da Universidade de Caxias do Sul (UCS). Endereço para correspondência: Rua Francisco Getúlio Vargas, 1130, Bloco E, Caxias do Sul (RS), 95070-560. E-mail: vebohm@bol.com.br

2 Mestre em educação, doutor em serviço social. Docente aposentado do Departamento de Serviço Social da Universidade Federal do Rio Grande do Sul (Ufrgs). E-mail: sacarlos@ufrgs.br

3 Mestre e doutor em Educação. Docente do Programa de Pós-Graduação em Educação (PPGEdu) da Universidade Federal do Rio Grande do Sul (Ufrgs). E-mail: johannes.ufrgs@gmail.com

$\rightarrow$ http://dx.doi.org/10.5335/rbceh.v13i2.6485

Recebido em: 08.11.2016. Aceito em: 10.04.2017. 
paldo estatístico, em que se explicita que, apenas no ano de 2014, foram 59.627 homicídios no país. Esse número choca quando percebido na totalidade, mas fica abrandado quando pulverizado em casos isolados. Ao considerar a idade das vítimas, a grande maioria das pessoas assassinadas de forma explícita está na faixa entre 15 e 29 anos de idade. É importante deixar claro que esses números são de homicídios comprovados, pois não dão visibilidade para as mortes que ocorrem em decorrência de outras formas de violência que também podem levar à morte, como maus tratos frequentes, porém menos impactantes fisicamente, negligência, violência psicológica, tão praticados contra velhos, recorte que será o mote deste estudo.

A par desse cenário, neste artigo, propõe-se discutir um aspecto quase invisível e silenciado da violência, que diz respeito àquela violência que ocorre quando alguém está cuidando de/ convivendo com um velho. Dessa forma, esta escrita nasce da articulação feita entre duas pesquisas desenvolvidas. A primeira pesquisa investigou as histórias de vida de três filhas cuidadoras informais de mães velhas, as quais não eram remuneradas para exercerem essa atividade. Como complicador, suas mães não possuíam mais autonomia e independência, necessitando, inclusive, do uso de fraldas geriátricas durante todo o período. Em alguns momentos nas entrevistas, as filhas chegaram a mencionar situações que poderiam ser associadas à violência, mas, durante a pesquisa, isso não ganhou destaque. No segundo estudo, o objetivo principal foi analisar fatores que conduziram à violência contra velhos com base na perspectiva dos agressores. Nesse outro estudo, oito pessoas consideradas agressoras foram entrevistadas por meio de narrativas, pelas quais puderam falar sobre a relação que tinham com seus pais. Ambos os projetos de pesquisa foram aprovados pelo Comitê de Ética em Pesquisa da Universidade Federal do Rio Grande do Sul por meio dos pareceres 020-2008 e 938.445, respectivamente, e aconteceram em municípios da serra gaúcha. Após, um novo questionamento gerou inquietação: há algo que ligue esses dois universos? Por que os atos agressivos identificados na pesquisa da dissertação não tiveram tanto destaque? Os dois estudos têm como lastro a velhice, entretanto, buscam produzir conhecimentos sobre como pessoas que convivem com velhos constroem essas relações.

Dessa forma, partindo dessas inquietações, buscou-se articular os dois estudos, uma vez que se acredita ser possível explicitar como as relações entre filhos e pais velhos e dependentes podem ser trabalhadas de maneira a minimizar, se não extinguir, as diferentes violências que podem ocorrer no cuidado. Violência e cuidado: dois temas que parecem contraditórios, talvez, por isso, passe imperceptível aos olhos menos atentos.

\section{Entre a violência e o cuidado}

Para discutir a violência que se esconde no cuidado, é imperativo mergulharmos um pouco na história das rela- 
ções humanas intergeracionais ao longo dos séculos. Frequentemente, a violência é apresentada como um "mau" da contemporaneidade, como consequência de uma sociedade impulsiva, imediatista e tecnológica, que não consegue valorizar e respeitar as pessoas mais velhas. Entretanto, da mesma forma que não é possível afirmar que todos os velhos são mal tratados atualmente, não há como sustentar certa visão nostálgica de que, no passado, as pessoas mais velhas eram reverenciadas. Simone de Beauvoir (1990), ao escrever sobre a velhice, no final da década de 60 do século passado, é taxativa ao mostrar a falta de status e o incômodo com o qual muitos velhos eram tratados não somente na sociedade europeia da época, mas também em comunidades/tribos antigas. Minois (1999) não poupa palavras para retratar os maus-tratos despendidos às pessoas idosas ainda na Grécia Antiga, onde havia um culto intenso à beleza juvenil e ao vigor físico. Essas constatações de formas de violência contra velhos há tanto tempo são reforçadas com a contemplação do $4^{\circ}$ mandamento cristão, que condena os maus-tratos em relação aos pais, ao nível de pecado, quando ressalta a importância de preservar essa relação: "Honrar pai e mãe". Quando da elaboração dos mandamentos, a lógica para a definição era manter a ordem na sociedade, dando espaço para as questões que a afetavam na ocasião. Reparem que, à época, não foram abordadas questões que condenassem crimes ambientais, tão em voga nos tempos atuais, pois não era uma preocupação. Todavia, sinalizava para a prática da violência contra a geração antecedente.

Essas constatações de violência contra os mais velhos ao longo da história não significam que, em algumas culturas, os velhos não fossem reverenciados. Na sociedade romana, Minois (1999) destaca que os grandes políticos, responsáveis pela governabilidade das cidades, eram pessoas mais velhas, por ser atribuídas a elas a serenidade e a sabedoria necessárias para o sucesso de todos. Muitas tribos indígenas até hoje enaltecem os mais velhos, por serem os detentores dos conhecimentos mais elementares para a sobrevivência do grupo.

Todavia, com as transformações demográficas que os países têm enfrentado, pelas quais se constata o aumento expressivo da expectativa de vida, principalmente entre as faixas etárias mais avançadas, exige-se uma reorganização da dinâmica familiar e da sociedade. Fato decorrente é grande parte dos longevos não conseguir manter níveis de autonomia e independência adequados, tão preconizado pela Organização Mundial da Saúde (2015) nas ações em prol do envelhecimento ativo.

Aprofundando os estudos sobre as mudanças populacionais, Camarano (2013) mostra que há um novo paradigma demográfico, em que as famílias crescem verticalmente e reduzem horizontalmente, o que pode ser constatado com a redução do número de filhos nas gerações mais novas, bem como com a existência de quatro, por vezes, cinco gerações vivas na mesma família. O que poderia ser motivo de muita alegria, a 
conquista da longevidade, passa a ser fonte de preocupação, pois a conquista de mais anos tem sido acompanhada pela vivência de doenças incapacitantes por mais tempo (KALACHE, 2013; CAMARANO; KANSO, 2010), necessitando cuidados especiais e, frequentemente, diuturnamente.

Quando a reorganização da dinâmica familiar torna-se imperativa para o cuidado de uma pessoa velha, é comum um familiar assumir essa função. Denominado de cuidador principal (ROBBE, 2008), ou primário (PERRACINI; NERI, 2006), por ser quem dá a assistência maior ao velho, garantindo a realização das atividades da vida diária, bem como os cuidados médicos, nem sempre ele tem a clareza do que o levou a assumir tal atribuição, nem a dimensão do que esta nova atividade vai impactar na sua vida. Esse cuidador também pode ser denominado de cuidador informal, pois não mantém vínculos trabalhistas com essa atividade.

Ao analisar o cuidado, parte-se de que essa não é uma ação isolada, mas é algo que ocorre em uma relação. Há a implicação das pessoas envolvidas na forma como esse cuidado se dará. No caso desse cuidado que ocorre dentro do universo familiar, são histórias de vida que vêm sendo engendradas há muitos anos e que podem ser atualizadas nessa nova forma de convivência. Devido à avalanche de emoções que atravessa a relação de um(a) filho(a), ou um(a) neto(a), cuidando de pai ou mãe, avó ou avô, as reações de ambos podem ser inesperadas. $\mathrm{O}$ reconhecimento da fragilidade do outro, que, até então, poderia ter sido uma referência de segurança, a percepção da finitude, que pode ser do próprio velho, ou a finitude do cuidador ao espelhar-se no familiar que cuida podem ser fonte de crescimento e aprendizagem, mas também de desestabilização emocional. Camarano e Kanso (2010) chamam a atenção para o fato de que a grande maioria dos velhos brasileiros não está institucionalizada, permanecendo em seus lares ou morando com familiares, o que, segundo as autoras, coloca as famílias como principais responsáveis pelo cuidado ou pelo "descuido" dessas pessoas.

Mas o que leva ao "descuido"? Se for lançado um olhar polarizado, será constatada a presença de um agressor e de uma vítima, costumeiramente, o papel de agressor sendo destinado ao mais jovem, nesse caso o cuidador, e o de vítima ao velho. Todavia, essa solução parece simplista demais para tentar entender como um espaço que era para ser acolhedor, repleto de aconchego, passa a ser um ambiente hostil e violentador. Nessa relação de cuidado, ambos têm que ser analisados: o cuidador e o velho, mas, também, a história das suas relações, sem ignorar o contexto atual.

Não raro, a notícia de que uma filha, praticamente sempre as mulheres assumem essa tarefa, terá que assumir o cuidado de um dos pais chega de maneira inesperada: após um acidente vascular cerebral, a sinalização médica para um quadro demencial, uma queda com fratura de fêmur ou bacia. Espaços físicos nas casas precisam ser adequados, a 
fim de acomodar mais uma pessoa ou de facilitar o deslocamento seguro. Diferentemente do que acontece na maioria das famílias com a chegada de um bebê, quando o espaço para acolhê-lo é organizado de maneira prazerosa e repleto de boas expectativas, frequentemente essas alterações nos domicílios quando para receber um velho é vista com insegurança, perda de espaço, incômodo, pois é sabido que a tendência do quadro é o agravamento, não o crescimento e a independência, como no caso de um bebê. Também essa experiência não está associada à realização de um desejo, mas, sim, da perda de um lugar de filha, assumindo o papel de cuidadora de uma mãe, por exemplo. Quando são lançados os olhares para os papéis que são perdidos, além do papel de filha, é comum perder o papel profissional e, por vezes, o papel de esposa, visto que a privacidade do casal acaba. Em pesquisa com cuidadoras de mães idosas, Bohm (2009) ressalta o quão desgastante fisica e psiquicamente é ser uma cuidadora informal de velhos em uma sociedade em que a rede de apoio não consegue dar conta das demandas dessa população. Também ficou clara a extrema dificuldade que as filhas cuidadoras tinham para encontrar tempo para o cuidado de si e dos papéis sociais que tinham até então. Constatou-se que, das entrevistadas casadas, nenhuma tinha um tempo para cuidar de si, nem privacidade prolongada com os seus companheiros. A porta do quarto do casal passa a não mais ser fechada, pois precisam estar atentas à movimentação e/ou ao som das mães; também não há mais tempo para cuidar de si, o que pôde ser constatado nos relatos, mas, também, na aparência de cada uma delas.

Outro papel que acaba sendo afetado é o profissional, acreditando que o quadro da mãe evoluiria rapidamente, uma das cuidadoras abriu mão da sua profissão para poder dedicar-se integralmente à mãe. $\mathrm{O}$ médico garantiu que a mãe teria pouco tempo de vida, o que levou essa filha a dedicar-se integralmente à mãe. Em outro plano, ficam marido, filhos, trabalho, ela própria, a fim de fazer o melhor para aquela mãe. Resultado de toda essa dedicação foi a sobrevida da mãe. O que era para ser um curto período, já passava de anos em casa, o que acaba sendo um complicador para o retorno dessa mulher à vida profissional, em um mercado que exige atualização constante.

A partir do resgate de parte da história de Madalena, é possível aprofundar um pouco na complexidade da relação de cuidado. Madalena se considerava privilegiada, pois carregava belas memórias da sua história ao lado dos pais. O pai, na ocasião das entrevistas, já era falecido. Ela não cogitou delegar a tarefa de cuidar da sua mãe para outra pessoa, por acreditar que era seu dever retribuir um pouco do que sua mãe havia feito por ela. Contudo, mesmo em um espaço repleto de afeto, provavelmente em função do nível de exigência que a atividade necessitava, às vezes a voz se alterava no trato e, em pensamento, chegava a desejar a morte daquela mãe, o que a deixava extremamente culpada. Outra filha cuidadora, Joana, em determinado momento da entrevista, disse: 
[...] eu poderia ser às vezes menos nervosa, eu poderia reclamar dela um pouquinho menos, porque eu não sou assim tão [...] tão santinha como eu costumo dizer o tempo todo. Eu fico nervosa [...] quando eu pego ela toda xixizada, eu digo: Mããe!! Por que tu faz isso? Não judia de mim [...].

A fala de Joana deixa claro o quanto a rotina do cuidado acaba sendo desgastante. Flasch, Lins e Carvalho (2016) auxiliam na compreensão dessa relação. Fizeram uma metanálise sobre o estresse do cuidador. No estudo, fica evidente o quanto cuidar de um familiar dependente é uma atividade exigente, que traz sobrecarga para o sujeito, e que os caminhos encontrados pelo cuidador e pela pessoa idosa vão depender do grau da patologia e do nível de dependência do velho, das condições internas do cuidador, das condições socioeconômicas disponíveis, mas, também, da história construída pelas pessoas envolvidas. Segundo as autoras, não é a situação estressante em si que determina o impacto que essa vai ter na vida dos cuidadores, mas como avaliam e conseguem recursos para lidar com ela.

É na busca da compreensão das histórias das vidas das pessoas envolvidas diretamente no cuidado dos velhos que se articulam as pesquisas de Bohm (2009, 2016), mencionadas no início deste artigo. Alguns anos após pesquisar as cuidadoras, a violência explícita contra velhos foi objeto de interesse. Ao ter acesso ao registro de denúncias de violência contra velhos em um município gaúcho, um recorte não intencional foi dado: a praticada por familiares, uma vez que os dados dos registros até fevereiro de 2015 eram, na sua grande maioria, de denúncias contra familiares violadores dos direitos dos velhos. Dos 217 registros, em cerca de $50 \%$ dos casos o violador era familiar, sendo que, em torno de $30 \%$ dos registros, não foi possível identificar quem era o agressor, o que pode aumentar ainda mais o percentual de agressores familiares.

Diante dessa constatação, o campo foi sendo explorado e, sem o intuito de julgá-los, mas de conhecê-los, oito agressores foram ouvidos. Os cenários eram, a princípio, bem distintos daqueles desbravados na pesquisa de 2009 . Mágoas, ressentimentos, sensação de ser preterido, injustiçado eram recorrentes nas falas dos entrevistados no estudo de 2016. Todos os entrevistados moravam com a pessoa que, naquele cenário, tinha sido vítima de agressão, o que coloca a coabitação, principalmente atrelada à fragilidade, como uma condição de alto risco para os velhos. Todavia, o que pôde ser constatado nas narrativas trazidas é que a violência, nessas famílias, não começou quando da fragilidade do velho, mas sempre permeou as relações entre os integrantes daqueles núcleos familiares. Os entrevistados foram claros ao resgatar memórias que remetiam ao sofrimento de violências na infância. Anita disse:

Tinha medo de acordar apanhando, porque se chamava uma vez e tu não saía da cama, tu saía apanhando.

Outra entrevistada, Isabela, relata sentir tratamento muito diferenciado 
dado, pela mãe, a ela quando comparado à forma de se relacionar com o irmão:

Porque a minha mãe, ela tem uma obsessão com o meu irmão, ela é assim uma tara, uma coisa assim, fora do comum. Se o meu irmão disser assim pra ela se atirar de uma coisa, ela vai. Ela faz uma diferença entre eu e ele enooorme.

A verbalização de lembranças dolorosas da infância não é exclusiva de agressoras mulheres. Sidinei narrou parte das suas memórias da infância em relação à mãe, dizendo:

Ela saía assim [...], ficava até uma semana fora de casa, até minhas tias deviam saber mais do que eu. Porque eu era pequeno, né. E ela me deixava dentro do prédio sozinho, saía fazer festa [...]

Os recortes das narrativas aqui apresentados mostram o quanto essas pessoas, que hoje são consideradas agressoras, carregam, nas suas histórias, marcas das lembranças de violência que as constituíram. Cabe a ressalva de que essas marcas não comprovam a ocorrência de atos violentos contra elas, mas expõem as cicatrizes que carregam da forma como conseguiram significar vivências das suas infâncias. Além destes registros, as narrativas servem de importantes pistas sobre a maneira como estas famílias foram conseguindo construir suas relações.

\section{Considerações finais}

Mas como se entrelaçam as histórias de Madalena, Joana, Sidinei, Anita, Isabela? Em um primeiro momento, o que é possível afirmar é que a qualidade das relações entre pais e filhos, quando os pais já velhos passam a precisar de cuidado, é, predominantemente, reflexo da forma como cada um dos envolvidos conseguiu significar as experiências vividas, em especial, como esses filhos as significaram. Ao ouvirmos Madalena e Joana, as quais nunca foram denunciadas por violação de direitos, percebe-se que elas se culpam por, em alguns momentos, atribuírem ao seu comportamento um caráter agressivo. $\mathrm{Na}$ fala de Joana, entende-se como um pedido de ajuda, devido à sobrecarga de afazeres, quando solicita para que a mãe não a judie. A impressão é de que, quando essas cuidadoras se reconhecem violentas, não é algo que ocorra intencionalmente, mas em uma situação de descontrole em decorrência da carga emocional e física envolvida, talvez, por isso, a violência não tenha ficado em relevo na ocasião daquele estudo. Entretanto, esse sentimento de culpa não aparece, em momento algum, ao longo das entrevistas realizadas no estudo que se propôs ouvir os agressores (BOHM, 2016). Esses filhos violentos também são vítimas de relações violentas. $O$ não reconhecimento de culpa pode ser devido à naturalização desse tipo de relação no universo em que foram criados. São filhos de pais que também podem ter sido frutos de relações violentas, o que acaba fazendo com que escoe, entre as gerações, a violência como principal herança.

Há caminhos que podem ser percorridos para essas duas realidades. Aos filhos cuidadores que, eventualmente, acabam gritando com seus pais em decorrência da sobrecarga, principalmente 
emocional, a saída parece ser mais curta, se houver vontade política. A criação de serviços de suporte ao cuidador de forma mais efetiva pode aliviar essa sobrecarga, garantindo uma atenção melhor aos velhos e uma vida digna aos cuidadores. No caso da violência instituída nas histórias familiares, mais do que culpabilizar um dos polos dessa relação, cabem ações mais efetivas, trabalhando os vínculos familiares antes que haja o rompimento definitivo. São famílias que tendem a resolver seus conflitos por meio dos atos, da violência, o que poderia ser, preventivamente, trabalhado com a mediação das questões conflitivas (VALE et al., 2015). Essas famílias precisam aprender outra forma de se relacionar, mais saudável, a fim de que novas gerações não sofram por herdar a violência dos seus progenitores.

\section{Stress between caring and violating: experience of descendant with old parents}

\section{Abstract}

Caring older people has been an ever present reality in today's society on the populational aging. Often, this care is executed by family members, who assumed this task without a preparation for it, which can cause increased stress in the relationship between caregiver and cared. Aware of this situation, this article proposes to discuss an almost invisible and muted violence, that occurs when someone is caring / living with an older person. To this end, a joint is made between two completed studies (BOHM, 2009, 2016), one about life stories of old caregivers and another about the violence against olds considering the perspective of the perpetrators. The results lead us to the importance of constructing qualified relationships among family members, as well the different meanings of the violent action as result of the kind of relationship between caregiver and cared.

Keywords: Elderly. Informal care. Violence.

\section{Referências}

BEAUVOIR, S. A Velhice. Rio de Janeiro: Nova Fronteira, 1990.

BOHM, V. Histórias de vida de cuidadores de idosos. 2009. Dissertação (Mestrado em Psicologia Social e Institucional) - Universidade Federal do Rio Grande do Sul, Porto Alegre, Rio Grande do Sul, 2009.

. Violência contra pessoas idosas: narrativas de agressores. 2016. $136 \mathrm{f}$. Tese (Doutorado em Educação) - Universidade Federal do Rio Grande do Sul, Porto Alegre, Rio Grande do Sul, 2016.

CAMARANO, A. A. O novo paradigma demográfico. Ciênc. saúde coletiva, Rio de Janeiro (RJ), v. 18, n. 12, p. 3446, dez. 2013.

CAMARANO, A. A.; KANSO, S. Como as famílias brasileiras estão lidando com idosos que demandam cuidados e quais as perspectivas futuras? A visão mostrada pelas PNADs. In: CAMARANO, A. A. (Org.). Cuidados de longa duração para população idosa: um novo risco social a ser assumido? Rio de Janeiro: Ipea, 2010. p. 93-122.

CERQUEIRA, D. et al. Atlas da Violência 2016 Ipea e FBSP. 2016. Disponível em: $<$ http://infogbucket.s3.amazonaws.com/arquivos/2016/03/22/atlas_da_violencia_2016. pd>. Acesso em: 14 out. 2016.

FLASCH, L. D.; LINS, A. E.; CARVALHO, E. B. Cuidado familiar a idosos física e cognitivamente frágeis: teoria, pesquisa e intervenção. In: FREITAS, E. V.; PY, L. 
Tratado de Geriatria e Gerontologia. 4. ed. Rio de Janeiro: Guanabara Koogan, 2016. p. 1476-1482.

KALACHE, A. The longevity revolution: creating a society for all ages. Adeleide Thinker in Residence 2012-2013. Adeleide: Governmente of South Australia, 2013. p. 9 .

MINOIS, G. História da velhice no ocidente: da Antiguidade ao Renascimento. Lisboa: Editora Teorema, 1999.

ORGANIZAÇÃO MUNDIAL DA SAÚDE. Resumo - Relatório Mundial de Envelhecimento e Saúde, 2015. Disponível em: <http:// sbgg.org.br/wp-content/uploads/2015/10/ OMS-ENVELHECIMENTO-2015-port.pdf>. Acesso em: 27 out. 2016.

PERRACINI, M. R.; NERI, A. L. Tarefas de cuidar: com a palavra, mulheres cuidadoras de idosos de alta dependência. In: NERI, A. L. (Org.). Cuidar de idosos no contexto da família: questões psicológicas e sociais. Campinas, SP: Alínea, 2006. p. 135-164.

ROBBE, J. O cuidador principal, e sua relação com os demais cuidadores. In: BORN, T. (Org.). Cuidar Melhor e Evitar a Violência - Manual do Cuidador da Pessoa Idosa. Brasília: Secretaria Especial dos Direitos Humanos, Subsecretaria de Promoção e Defesa dos Direitos Humanos, 2008. p. 64-69.

VALE et al. Mediação de conflitos de violência intrafamiliar contra pessoas idosas: uma proposição não jurídica. Textos\&Contextos, Porto Alegre (RS), v. 14, n. 1, p. 104-114, jan./jun. 2015. 